\title{
Passive Immunity for Coronavirus Disease 2019: A Commentary on Therapeutic Aspects Including Convalescent Plasma
}

\author{
Paul F. Lindholm, MD ${ }^{1} \quad$ Glenn Ramsey, MD ${ }^{1}$ \\ ${ }^{1}$ Department of Pathology, Feinberg School of Medicine, \\ Northwestern University, Chicago, Illinois \\ 2 Division of Hematology-Oncology, Department of Medicine, \\ Feinberg School of Medicine, Northwestern University, \\ Chicago, Illinois
}

Hau C. Kwaan, MD,FRCP2

Semin Thromb Hemost 2020;46:796-803.

\begin{abstract}
Address for correspondence Paul F. Lindholm, MD, Department of Pathology, Feinberg School of Medicine, Northwestern University, 303 East Chicago Avenue, Ward 3-140 W127, Chicago, IL 60611 (e-mail: P-lindholm@northwestern.edu).
\end{abstract}

\begin{abstract}
Keywords

- COVID-19

- MERS

- SARS

- immunity

- immunoglobulin

- convalescent plasma

In the ongoing pandemic of coronavirus disease 2019 (COVID-19), the novel virus SARSCoV-2 (severe acute respiratory syndrome coronavirus 2 ) is infecting a naïve population. The innate immunity of the infected patient is unable to mount an effective defense, resulting in a severe illness with substantial morbidity and mortality. As most treatment modalities including antivirals and anti-inflammatory agents are mostly ineffective, an immunological approach is needed. The mechanism of innate immunity to this viral illness is not fully understood. Passive immunity becomes an important avenue for the management of these patients. In this article, the immune responses of COVID-19 patients are reviewed. As SARS-CoV-2 has many characteristics in common with two other viruses, SARS-CoV that cause severe acute respiratory syndrome (SARS) and MERS-CoV (Middle East respiratory syndrome coronavirus) that causes Middle East respiratory syndrome (MERS), the experiences learned from the use of passive immunity in treatment can be applied to COVID-19. The immune response includes the appearance of immunoglobulin M followed by immunoglobulin $G$ and neutralizing antibodies. Convalescent plasma obtained from patients recovered from the illness with high titers of neutralizing antibodies was successful in treating many COVID-19 patients. The factors that determine responses as compared with those seen in SARS and MERS are also reviewed. As there are no approved vaccines against all three viruses, it remains a challenge in the ongoing development for an effective vaccine for COVID-19.
\end{abstract}

In early December 2019, a cluster of acute respiratory infections in Wuhan, China, quickly spread globally and become a pandemic. This was identified as acute viral pneumonia caused by a novel coronavirus, 2019-nCov, later named SARS-CoV-2 (severe acute respiratory syndrome coronavirus 2). ${ }^{1-4}$ This virus has $79.5 \%$ homology to SARS-CoV, the virus that caused the severe acute respiratory syndrome (SARS) and shares many clinical and pathological characteristics with SARS and the Middle East respiratory syndrome (MERS). ${ }^{5,6}$ These coro- naviruses are highly contagious to a naïve population. ${ }^{7}$ In a significant number of patients, the disease rapidly progressed from an acute respiratory tract infection with fever, cough, sore throat, headache, and fatigue to severe pneumonia with progressive dyspnea, often complicated by acute respiratory distress syndrome (ARDS). ${ }^{3,8,9}$ Unfortunately, coronavirus disease 2019 (COVID-19) is poorly responsive to antiviral agents such as remdesivir and lopinavir/ritonavir. ${ }^{10,11}$ Other agents such as hydroxychloroquine, tocilizumab, and sarilumab are published online June 11, 2020
Issue Theme Maintaining Hemostasis and Preventing Thrombosis in COVID-19 -Part I; Guest Editors: Emmanuel J. Favaloro, PhD, FFSc (RCPA), and Giuseppi Lippi, MD.
Copyright $\odot 2020$ by Thieme Medical Publishers, Inc., 333 Seventh Avenue, New York, NY 10001, USA.

Tel: $+1(212) 760-0888$.
DOI https://doi.org/ $10.1055 / \mathrm{s}-0040-1712157$. ISSN 0094-6176. 
met with varying successes. ${ }^{12,13}$ Thus, an immunological approach to treatment is highly essential at this stage of our knowledge. ${ }^{14}$ As the defense by innate immunity for this virus is not fully understood, treatment relies on passive immunity. Here, we review the basic concepts of passive immunity for viral infections and the effectiveness of convalescent plasma, immunoglobulins, and vaccines.

The patient's course with COVID-19 usually begins with fever and mild respiratory symptoms. During this time, the virus may be actively replicating. SARS-CoV-2 infects pulmonary alveolar type 2 cells through the binding of aerosolized virus with angiotensin-converting enzyme 2 (ACE2) expressing target cells. ${ }^{14}$ The resulting lower respiratory tract infection can lead to vascular leakage, fibrin deposition, alveolar cell necrosis, hyaline membrane formation, and diffuse alveolar damage, resulting in ARDS and respiratory failure. ${ }^{15}$ Patients with severe COVID-19 infection have high levels of proinflammatory cytokines, causing a cytokine storm that could promote viral sepsis, inflammatory lung injury, ARDS, hypotension, and multiorgan failure. ${ }^{4,16}$ An early report of the mortality rate for COVID-19 was up to $15 \%$, depending on age and comorbid conditions. ${ }^{16}$ By comparison, in the first 1,425 cases of SARS in Hong Kong, the estimated case fatality rate was $13.2 \%$ for patients less than 60 years old and $43.3 \%$ for patients $\geq 60$ years old. ${ }^{17}$ SARS infection in the pediatric age group is often less severe but can also lead to ARDS and respiratory failure in some patients. $^{18}$

\section{Immune Response Mechanism}

The host response to virus-infected cells likely plays an important role in the damage to respiratory cells. ${ }^{15}$ The pulmonary pathology leads to influx of neutrophils and monocytes/macrophages and results in a hyperproduction of proinflammatory cytokines and a cytokine storm. ${ }^{14}$ Severe coronavirus infections are accompanied by increased levels of several proinflammatory cytokines including IP-10 (interferon- $\gamma$-inducible protein 10), MCP-1 (monocyte chemoattractant protein-1), MIP-1A (macrophage inflammatory protein$1 \mathrm{~A}$ ), and TNFR2 (tumor necrosis factor- $\alpha$ receptor 2 ), especially in the severe cases requiring intensive care unit care. ${ }^{16}$ This pattern of response is similar to those seen in SARS ${ }^{19}$ and MERS. ${ }^{20}$ This innate immune response is shown in the peripheral blood as increased total neutrophils in 38\% patients, reduced total lymphocytes in 35\%, increased serum IL-6 (interleukin-6) in 52\%, and increased C-reactive protein in $84 \%$,within the first cohort in Wuhan. ${ }^{4}$ The magnitude of these changes was also correlated with the severity of the disease as well as mortality. ${ }^{21}$ In most viral infections, an effective antiviral immune response involves the innate immune system leading to viral recognition, cellular signaling, and type I interferon (IFN) response to suppress viral replication and dissemination. ${ }^{22,23}$ Severe SARS and MERS coronavirus infections appear to dysregulate the IFN response and lead to increased levels of neutrophils and macrophages in the infected lung tissues, leading to lung injury and ARDS in severe COVID-19 infections. ${ }^{24-26}$ The acute phase of SARS is also associated with lymphopenia and decreased dendritic and T cells. $^{23,27}$

Antibodies play a dual role in communicating the presence of a pathogen to immune effector cells and complement system and interfering with the viral life cycle by blocking viral entry into and egress from the host cell. ${ }^{28}$ The coronaviruses have a lipid bilayer envelope, which is co-opted from the host and contains surface-exposed viral glycoproteins to aid in host recognition and entry. The viral glycoproteins are the major targets of host antibodies and in some cases, may be the only exposed viral antigen. Viruses may have developed mechanisms to avoid antibody responses including hiding their antigenic epitopes, producing immune decoys, and causing immunosuppression. Viral entry into the host cell requires cell attachment and fusion of host and viral membranes caused by glycoprotein conformational change that forms pores to allow the virus to enter the cell cytoplasm. Viral replication occurs by various mechanisms, depending on the virus, within the cell, which ultimately leads to new virus shedding from the cell surface. Neutralizing antibodies disrupt viral entry during these processes. Neutralizing antibodies may also block viral budding and shedding from the infected cell. In addition, nonneutralizing activities of antibodies may tag the virus particle for destruction by antibody-dependent cellular cytotoxicity or complement activation or viral agglutination. ${ }^{28-32}$ Notably, in COVID-19, the use of corticosteroids in treating the pulmonary complications impairs the aforementioned immune processes and prolongs the period of viral shedding by the patient. ${ }^{33-36}$

The majority of patients who recover from severe coronavirus infections develop a humoral immune response with neutralizing antibodies, which may then limit the infection and prevent reinfection. In SARS, seroconversion has been detected between 4 and 14 days in most patients, with neutralizing antibodies being detected up to 2 years after the infection. ${ }^{37,38}$ Seroconversion with MERS infection was reported in the second and third weeks of the disease. Patients with severe outcomes have delayed or weak antibody responses. ${ }^{37}$ COVID-19 patients developed a virusspecific immunoglobulin $M$ (IgM) peak 9 days after the disease onset, and the transition to immunoglobulin $G$ (IgG) occurred within the second week. The IgM is generally gone by 14 days, and its determination can be helpful in determining when the patient was infected as well as the stage of disease. Around day 20, neutralizing antibody to SARS-CoV-2 were found at titers of $1: 40$ to $1: 80 .^{4}$ The detection for both the IgM and IgG are carried by the socalled "rapid tests." ${ }^{39}$ Neutralizing antibodies are found to be present in SARS patients up to 2 years following recovery. ${ }^{40}$

\section{Passive Immune Therapy}

With the population not previously exposed to SARS-CoV-2, passive immunity has to be developed for therapeutic purposes. Monoclonal antibodies have been previously made for SARS and MERS. The receptor-binding domain (RBD) of the spike protein on SARS-CoV and MERS-CoV is the principal antigenic component responsible for inducing host immune response. ${ }^{41}$ Since the spike protein is the component of 
SARS-CoV and MERS-CoV that attaches to their respective receptors on host cells, namely ACE2 for SARS-CoV and dipeptidyl peptidase-4 (DPP4) for MERS-CoV, antibodies directed at this epitope would block the entry of the virus to the host. These antibodies and their mechanism of action are discussed elsewhere. ${ }^{42}$ A recent review evaluated the potential therapeutic monoclonal antibodies and animal models of MERS. ${ }^{43,44}$ They described seven neutralizing antibodies panned with full-length spike protein on paramagnetic proteoliposomes and mammalian cells with the ability to bind to MERS-CoV RBD with potent neutralizing activity. Animal model studies and clinical trials are pending. By extrapolation, therapeutic monoclonal antibodies could be developed for SARS-CoV-2. ${ }^{45}$

Passive immunity can be conferred to patients by using immunoglobulin with high titers of neutralizing antibodies or by plasma obtained from convalescent patients.

\section{Immunoglobulin Strategies}

Hyperimmunoglobulin with high titers of virus-specific neutralizing antibodies have the potential to improve outcomes for patients with respiratory viral infections. A small multivariate trial of hyperimmunoglobulin reduced mortality and viral load in patients in the 2009 influenza A/H1N1 pandemic. ${ }^{46}$ However, results have varied in several trials and would need to be tested in specific diseases and clinical situations to determine the possible benefit. ${ }^{47}$ Several biotherapeutics firms are working with the U.S. Food and Drug Administration (FDA) to develop plasma-derived and monoclonal hyperimmunoglobulin therapies for severe acute respiratory infections (SARIs) including COVID-19. Although purified hyperimmunoglobulin products may have value in treating severe respiratory viral infections, convalescent plasma is the only therapeutic strategy that is available for early use in response to the COVID-19 pandemic. $^{48}$

Immunoglobulin titers can be measured using enzymelinked immunosorbent assay (ELISA) immunofluorescence assays or by testing their ability to precipitate a particulate antigen. Antibody titers can also be tested for their ability to block viral hemagglutination or to inhibit virus infectivity. Viral neutralization assays only detect antigen-antibody interactions that block virus replication. ${ }^{49}$ The viral plaque reduction neutralization test (PRNT) is the gold standard for determining neutralizing antibody titer. It requires a biosafety level 3 facility to perform.

\section{Convalescent Plasma Studies for Severe Acute Viral Infectious Diseases}

The use of convalescent plasma collected from patients recovering from acute viral diseases have been used for Ebola, influenza, SARS and MERS, and, more recently, COVID-19. ${ }^{46-48}$

\section{Influenza A}

An early meta-analysis of the 1918 influenza A/H1N1 pandemic showed that the use of convalescent plasma reduced the case fatality rate by $21 \%{ }^{50}$ For patients who received convalescent plasma during this influenza A pandemic, minor complications reported included fever, chills, and sweats. ${ }^{51-53}$ A recent meta-analysis was performed on 32 studies evaluating the effectiveness of convalescent plasma and hyperimmunoglobulin for the treatment of SARIs including SARS and severe influenza A. ${ }^{54}$ The studies consistently reported mortality reduction, particularly when the convalescent plasma was given soon after symptom onset. A statistically significant reduction in mortality was found with convalescent plasma compared with placebo or control in post hoc analysis. Serious adverse events were not reported in studies after treatment with convalescent plasma for influenza A (H1N1) and H5N1. ${ }^{54}$ However, the studies were determined to be frequently low in quality, lacking control groups and having a high risk of bias. Although the study found that convalescent plasma appeared safe and may reduce mortality, well-controlled and designed clinical trials were recommended.

In a prospective cohort study of patients with severe influenza A H1N1 infection in the 2009 pandemic, treatment with convalescent plasma showed a significant reduction in the relative risk of mortality (odds ratio: 0.20 ; 95\% confidence interval 0.06-0.69; $p=0.011) .{ }^{55}$ Furthermore, a multicenter, prospective, double-blind, randomized controlled trial (RCT) showed that the use of influenza A H1N1 convalescent plasma resulted in a lower viral load and reduced mortality within 5 days of symptom onset in patients with severe influenza A H1N1 infection. ${ }^{46}$

A phase 2 multicenter randomized study of immune plasma treatment of patients with severe influenza A disease did not show benefit in the primary end point including normalization of respiratory status by the 28th day; however, the patients tolerated the treatment well and showed several improved secondary end points including improved clinical status, less intensive care, and fewer hospital days. ${ }^{56}$ A subsequent blinded randomized prospective phase 3 trial showed that high-titer convalescent plasma (compared with low-titer plasma) provided no significant clinical benefit in terms of improved clinical status or reduced common serious adverse event for patients undergoing hospital treatment for severe seasonal influenza A. ${ }^{57}$ The authors concluded that treatment with high-titer plasma produced insufficient benefit to justify its use to treat severe influenza A patients.

\section{Severe Acute Respiratory Syndrome}

Convalescent plasma transfusion may be beneficial in the treatment of critically ill patients with SARS infection. ${ }^{58}$ Eighty patients were treated with 160 to $640 \mathrm{~mL}$ of convalescent plasma around day 14 (range: 7-30 days). The convalescent plasma was collected from donors who recovered from SARS infection and were afebrile for at least 7 days, off oxygen supplementation, and at least 14 days from symptom onset. Thirty-three patients had a good clinical outcome, with discharge by day 22 following the onset of SARS symptoms; they were given convalescent plasma earlier than the patients with a poor outcome. Patients who received convalescent plasma after day 14 had a longer hospital stay and a higher mortality rate. The timing of 
convalescent plasma administration was significantly affected by plasma availability. There was no correlation found between clinical outcome and either the plasma volume or the coronavirus antibody titers. No immediate adverse effects including infections of plasma transfusion were reported.

The effectiveness of convalescent plasma was analyzed in a meta-analysis of 32 studies of SARS coronavirus and severe acute viral respiratory infections including infections with SARS. ${ }^{54}$ The study indicated that convalescent plasma treatment was associated with reduced mortality, especially when the plasma was administered early after onset of symptoms. A post hoc meta-analysis showed that treatment with convalescent plasma led to a statistically significant reduction in the pooled odds of mortality. A meta-analysis of eight observational studies reported that SARS coronavirus infected patients who received convalescent plasma showed improved mortality outcomes with severe infections. ${ }^{54}$ The meta-analysis study indicated that many of the studies were of low or very low quality, lacked control groups, and had a moderate or high risk of bias.

Areas for future research are recommended in welldesigned clinical trial protocols. The authors recommend ideally RCTs or observations studies with standard minimum dataset needed. Future studies should be designed to determine the mode of action and optimal dose of convalescent plasma to achieve good clinical outcomes. The International Severe Acute Respiratory and Emerging Infection Consortium is developing a clinical trial protocol to investigate passive immunotherapy for severe acute respiratory and emerging infection. ${ }^{54,59}$ Viral load by quantitative viral nucleic acid testing and viral antibody titers were found to be useful in defining the virologic and immunological kinetics that lead to improved clinical outcomes. It will be important to define the optimal plasma volume, number of doses, and quantitative neutralizing antibody titers to determine the optimal amount of antibody that is needed to effectively inhibit virus replication. In addition to the primary end point of mortality, useful secondary clinical end points should be considered, including duration of critical care support, sepsis, organ failure, length of hospital stay, serious adverse events, recurrence of severe disease, and readmission for complications.

During the 2003 SARS outbreak, the use of convalescent plasma was reported from the Prince of Wales Hospital in Hong Kong. ${ }^{58}$ The study analyzed the treatment of 80 patients who had clinical deterioration despite treatment with methylprednisolone and received treatment with convalescent plasma around day 14 from the onset of symptoms. The patients received between 600 and $900 \mathrm{~mL}$ of convalescent plasma collected by apheresis in 200- to 225$\mathrm{mL}$ aliquots. They reported that patients with a good outcome were given convalescent plasma earlier in the clinical course, before day 14 . Patients who received convalescent plasma earlier had significantly higher rate of discharge from the hospital by the 22nd day and significantly lower mortality. There were no adverse effects including infections. Plasma availability was identified as a major determinant of the timing of convalescent plasma administration. $^{58}$

\section{Middle East Respiratory Syndrome}

A study protocol has been developed to evaluate convalescent plasma therapy for patients with MERS syndrome. ${ }^{60}$ Due to the lack of data to support convalescent plasma treatment for MERS-CoV infection, a protocol was developed for a two-phase study to determine the feasibility of collecting convalescent plasma from donors who have significant anti-MERS-CoV antibodies. In the second phase, the plan was to treat patients with convalescent plasma to determine the safety, feasibility, and effect on viral load and illness. The aim was to determine the most appropriate neutralizing antibody dose and timing for a future powered RCT to determine the effect on the treatment on mortality.

Three patients with severe MERS-CoV respiratory failure received convalescent plasma from donors collected within their third week of illness. ${ }^{61}$ Two of the four donors had detectable neutralizing antibody activity by PRNT assay. Two patients received mechanical ventilation and one received extracorporeal membrane oxygenation support. Only one patient had a meaningful increase in MERS-CoV antibody titer in response to the transfusion of convalescent plasma. All of the patients recovered and were discharged from the hospital. However, due to the small study size and lack of controls, the effectiveness of the treatment could not be evaluated. The authors recommend that donor plasma should be tested for antiviral antibody activity with a PRNT titer of $\geq 1$ :80.The authors further recommend that the efficacy of convalescent plasma transfusion be evaluated in endemic countries with a well-designed clinical protocol.

\section{Severe Acute Respiratory Syndrome Coronavirus 2}

An early uncontrolled study of 10 patients with severe COVID-19 infection were treated with a single 200-mL dose of convalescent plasma, which had neutralizing titers of greater than $1: 640 .{ }^{62}$

Donors were 3 weeks post onset of illness and 4 days post discharge. In the recipients, the clinical symptoms and oxyhemoglobin levels were improved within 3 days of transfusion along with improvement of lung lesions by 7 days. Transfusion of convalescent plasma was temporally associated with a change to undetectable viral loads. This report showed that convalescent plasma was well tolerated and has the potential to improve clinical outcomes for patients with severe SARS-CoV-2 infections.

In another report, five patients with severe COVID-19 infections were treated with convalescent plasma transfusion to determine its potential benefit for the treatment of SARS. ${ }^{63}$ These patients had continuously high viral load despite antiviral treatment with rapidly progressing pneumonia. Their $\mathrm{PAO}_{2} / \mathrm{FIO}_{2}$ ratio was less than 300 , indicating ARDS, and they required mechanical ventilation. They received $400-\mathrm{mL}$ aliquots of convalescent plasma between 10 and 22 days after admission. The convalescent plasma had SARS-CoV-2-specific antibody (IgG) binding titer of greater than 1:1,000 using ELISA and viral neutralization titer 
greater than 40 by end-point dilution. Four of five patients treated with convalescent plasma defervesced within 3 days and had improved Sequential Organ Failure Assessment scores and increased $\mathrm{PO}_{2} / \mathrm{FiO}_{2}$ ratios. The viral loads of the treated patients decreased and became negative within 12 days after the transfusion. Also, the SARS-CoV-2 specific ELISA and neutralizing antibody titers increased. The ARDS resolved in four patients at 12 days after transfusion. Three patients were weaned from mechanical ventilation within 2 weeks of treatment and were discharged from the hospital. Two of the patients were receiving mechanical ventilation and were in stable condition at 37 days. There were no adverse events reported.

The role of convalescent plasma and how to use it for treating COVID-19 was recently reviewed. ${ }^{64}$ Neutralizing antibody responses peaked at 4 months and then decreased to undetectable levels in 16 to $48 \%$ of patients at 36 months. A significant portion of patients who had detectable antibodies at 36 months had persistent viral neutralizing activity. The antibody neutralizing titer varied from $1: 12$ to $1: 512$ in convalescent plasma, with a geometric mean of $1: 60 .{ }^{65}$ These antiviral titers have been found to generally correlate with the initial viral load and the severity of illness for Influenza A/ H1N1 and MERS infections. ${ }^{66,67}$

Convalescent plasma is a preferred product for passive immunotherapy because it can be collected by apheresis in larger volumes and more frequently with little impact on the patient's hemoglobin level. The authors recommend plasma collection at least 14 to 28 days postresolution of COVID-19 infection symptoms. Based on previous SARS-CoV-1 studies, the anti-SARS-Cov-2 neutralizing antibody titer should be greater than 1:40.49,68,69 The convalescent plasma donors must qualify as allogeneic blood donors and should be obtained from female donors negative for human leukocyte antigen (HLA) antibodies or from male donors. When double plasma units are collected by apheresis, the maximum plasma donation frequency in the United States is normally 28 days. The plasma may be cryopreserved and stored frozen at less than $-18^{\circ} \mathrm{C}$ for later clinical use. Several studies have shown evidence in favor of early treatment before seroconversion and preferably within the first 5 days of severe disease, with convalescent plasma to patients at high risk of clinical deterioration.

\section{Adverse Effects of Convalescent Plasma}

No serious adverse events have been reported with convalescent plasma transfusions in a 2015 systematic review or in a trial for Ebola disease. ${ }^{64}$ Minor adverse events, mostly temperature increase and/or itching or skin rash, were observed in $8 \%$ of patients. There are two case reports of possible transfusion-related acute lung injury (TRALI) reported on convalescent plasma in a patient with Ebola disease and in another patient with MERS-CoV; however, the plasmas did not contain anti-HLA or antihuman neutrophil antibodies.

Antibody-dependent enhancement (ADE) is a theoretical concern of passive plasma antibody therapy. In ADE, cross- reacting antibodies from one strain of virus may bind to another strain and facilitate Fc-receptor-mediated cell entry of the virus, causing more severe disease. However, in coronaviruses, most observations were made in animal studies, and there are limited epidemiological studies on humans. $^{70}$

\section{Recommended Procedure for Convalescent Plasma Use}

Based on previous studies, the transfusion should occur early in the course of the severe COVID-19 infection, ideally within 5 days. ${ }^{58,64}$ It is recommended to begin with one unit of plasma ( 200-250 mL) infused at a slow rate with close monitoring for adverse transfusion reactions including allergic and febrile reactions, circulatory overload, and possible evidence of systemic or pulmonary inflammatory reactions. If available, repeat convalescent plasma transfusions can be considered in the next 24 to 48 hours, depending on how the patient tolerated the first transfusion and on the clinical response.

A comprehensive discussion on the workflow and logistics for plasma collections from patients recovered from COVID-19 infections was recently published. ${ }^{48}$ Eligibility for convalescent plasma donation includes (1) a history of COVID-19, as confirmed by either approved molecular testing on a nasopharyngeal swab specimen or the presence of plasma SARS-CoV-2 antibodies, and (2) evidence of resolution of COVID-19 at donation with $\geq 14$ days without COVID-19 symptoms (FDA Guidance, May 2020). ${ }^{71}$ If needed, the predonation screening is performed by the provider before the donor is referred to the blood collection facility. If the donor has been pregnant, the collection facility must screen for HLA antibodies to reduce TRALI risk in patients who already may have ARDS. Plasma collection $\geq 14$ days after resolution of symptoms provides the best likelihood of having high titers of anti-SARS-CoV-2 antibodies. ${ }^{62}$ High neutralizing antibody titers are, ideal but standard quantitative ELISA titers are more often available. Donors also must qualify as allogeneic blood donors through standard screening and testing, as specified, for example, by the FDA. Although plasma is usually collected by apheresis, a standard starting dose for an average sized patient would be one (200-250 mL) plasma unit. A work flow diagram is shown in -Fig. 1.

There are three pathways in the United States for providing access to convalescent plasma for patients with SARSCoV-2 infections ${ }^{71}$ : clinical trials; a national expanded access treatment protocol to provide one unit of plasma to patients $\geq 18$ years old under a central investigational new drug (IND) protocol; and for patients without access to clinical trials or the expanded access protocol, single-patient emergency IND (eIND) treatment after local Institutional Review Board approval and FDA approval.

Several clinical trials have been proposed to evaluate SARS-CoV-2 convalescent plasma for postexposure prophylaxis for adults who have been exposed but not yet symptomatic, patients with mild disease, patients with moderate 
Convalescent

Donor
History recent COVID-19 infection with

positive RNA test for SARS-CoV-2 or

plasma SARS-CoV-2 antibodies

\section{4 - 27 days symptom free w/negative follow-up nasopharyngeal or blood RNA test for SARS-CoV-2

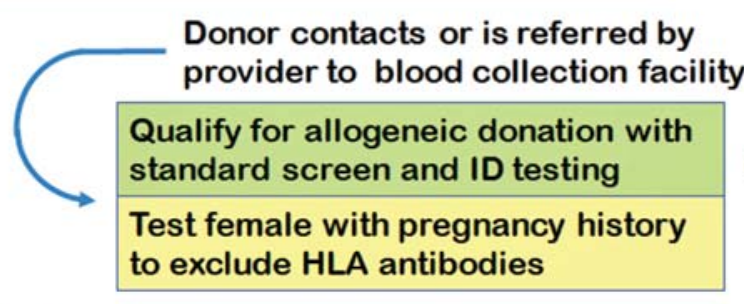 \\ Donor contacts or is referred by provider to blood collection facility \\ Qualify for allogeneic donation with standard screen and ID testing to exclude HLA antibodies}

Patient's doctor requests convalescent plasma for patient under appropriate approval mechanism

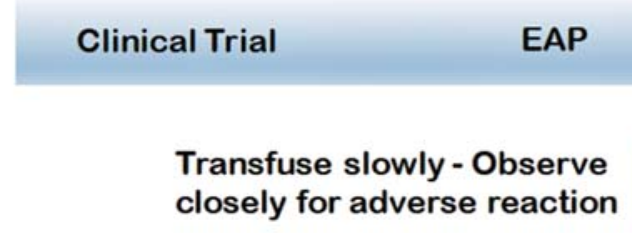
Transfuse slowly- Observe
closely for adverse reaction
Collect convalescent plasma

$\longrightarrow$ Viral titer testing चा山्य

Fig. 1 Workflow for convalescent plasma collection from SARS-CoV-2 patients. A donor may be eligible to provide convalescent plasma if they have a history of COVID-19 infection confirmed by either approved molecular testing on a nasopharyngeal swab specimen at the time of illness or a positive serological test for SARS-CoV-2 antibodies after recovery. COVID-19 convalescent plasma is collected from individuals who must have complete resolution of symptoms at least 14 days before the donation per FDA Guidance on Investigational COVID-19 Convalescent Plasma, May 1, 2020. A negative result for COVID-19 by a diagnostic test is not necessary to qualify the donor. ${ }^{67}$ If needed, the predonation screening is performed by the provider before the donor is referred to the blood collection facility. If the donor is pregnant, the collection facility must screen for HLA antibodies to reduce TRALI risk in patients who already may have ARDS. Plasma collection $\geq 14$ days after resolution of symptoms provides the best likelihood of having high titers of anti-SARS-CoV-2 antibodies. ${ }^{59}$ Convalescent plasma may be provided to patients with SARSCoV-2 infections through one of three approval pathways: (1) clinical trials, (2) national EAP under a central IND protocol, and (3) single-patient eIND treatment after local Institutional Review Board approval and FDA approval. COVID-19, coronavirus disease 2019; EAP, expanded access treatment protocol; eIND, emergency investigational new drug; FDA, U.S. Food and Drug Administration; HLA, human leukocyte antigen; ID, infectious disease testing required by the FDA; IND, investigational new drug; SARS-CoV-2, severe acute respiratory syndrome coronavirus 2; TRALI, transfusion-related acute lung injury.

disease, rescue intervention for patients receiving mechanical ventilation, and pediatric patients. Information on adverse events and COVID-19 outcomes after plasma therapy will also be collected from the expanded access program and eIND cases. ${ }^{48}$

\section{Vaccines}

Currently, there are no vaccines available for COVID-19. Different types of vaccines had in the past been developed for SARS and MERS, but none has yet been approved. ${ }^{72}$ The RBD of SARS-CoV spike protein has been shown to induce neutralizing antibodies. ${ }^{73,74}$ Subunits of the $S$ protein of SARS-CoV and MERS-CoV are currently being used by different manufacturers employing various technologies. In one, the S-trimer of SARS-CoV-2 has been shown to confer antigen-specific neutralizing antibodies. Others are $\mathrm{DNA}^{75}$ and $\mathrm{mRNA}$ vaccines. One major concern is the somewhat ironic phenomenon of ADE, as mentioned previously with use of convalescent plasma, in which the vaccinated person responds with virus-specific antibodies that can facilitate virus entry into the host cell through the Fc-receptor path- way. ${ }^{76-78}$ As these developments are evolving at a rapid pace, further discussion is currently beyond the scope of this article.

\section{Conclusion}

The immune system is a major means to combat severe viral acute respiratory diseases. With the rapid onset of the COVID-19 pandemic in a naïve population, there is limited defense by the body's innate immunity. As there is a lack of other effective preventive and therapeutic measures, patients suffering from COVID-19 may benefit from passive immunity to mitigate the severe complications of the disease. This can be achieved using hyperimmunoglobulin or convalescent plasma. Of these, convalescent plasma is most readily available. Past experience has shown benefits of convalescent plasma in influenza, Ebola, SARS, and MERS. It is hopeful that the limited reports on its successful use in this pandemic will be verified in current clinical trials.

Conflict of Interest

None. 


\section{References}

1 Guan WJ, Liang WH, Zhao Y, et al; China Medical Treatment Expert Group for Covid-19. Comorbidity and its impact on 1590 patients with Covid-19 in China: a nationwide analysis. Eur Respir J 2020: 2000547

2 Guan WJ, Ni ZY, Hu Y, et al; China Medical Treatment Expert Group for Covid-19. Clinical characteristics of coronavirus disease 2019 in China. N Engl J Med 2020 (e-pub ahead of print) . Doi: 10.1056/NEJMoa2002032

3 Guo YR, Cao QD, Hong ZS, et al. The origin, transmission and clinical therapies on coronavirus disease 2019 (COVID-19) outbreak - an update on the status. Mil Med Res 2020;7(01):11

4 Zhou P, Yang XL, Wang XG, et al. A pneumonia outbreak associated with a new coronavirus of probable bat origin. Nature 2020;579 (7798):270-273

5 Yin Y, Wunderink RG. MERS, SARS and other coronaviruses as causes of pneumonia. Respirology 2018;23(02):130-137

6 Lau YL, Peiris JS. Pathogenesis of severe acute respiratory syndrome. Curr Opin Immunol 2005;17(04):404-410

7 Li G, Fan Y, Lai Y, et al. Coronavirus infections and immune responses. J Med Virol 2020;92(04):424-432

8 Giwa AL, Desai A, Duca A. Novel 2019 coronavirus SARS-CoV-2 (COVID-19): an updated overview for emergency clinicians. Emerg Med Pract 2020;22(05):1-28

9 Adhikari SP, Meng S, Wu YJ, et al. Epidemiology, causes, clinical manifestation and diagnosis, prevention and control of coronavirus disease (COVID-19) during the early outbreak period: a scoping review. Infect Dis Poverty 2020;9(01):29

10 Chu CM, Cheng VC, Hung IF, et al; HKU/UCH SARS Study Group. Role of lopinavir/ritonavir in the treatment of SARS: initial virological and clinical findings. Thorax 2004;59(03):252-256

11 Arabi YM, Asiri AY, Assiri AM, et al; and the Saudi Critical Care Trials group. Treatment of Middle East respiratory syndrome with a combination of lopinavir/ritonavir and interferon- $\beta 1 \mathrm{~b}$ (MIRACLE trial): statistical analysis plan for a recursive two-stage group sequential randomized controlled trial. Trials 2020;21(01):8

12 Touret F, de Lamballerie X. Of chloroquine and COVID-19. Antiviral Res 2020;177:104762

13 Gao J, Tian Z, Yang X. Breakthrough: chloroquine phosphate has shown apparent efficacy in treatment of COVID-19 associated pneumonia in clinical studies. Biosci Trends 2020;14(01):72-73

14 Prompetchara E, Ketloy C, Palaga T. Immune responses in COVID19 and potential vaccines: Lessons learned from SARS and MERS epidemic. Asian Pac J Allergy Immunol 2020;38(01):1-9

15 Newton AH, Cardani A, Braciale TJ. The host immune response in respiratory virus infection: balancing virus clearance and immunopathology. Semin Immunopathol 2016;38(04):471-482

16 Huang C, Wang Y, Li X, et al. Clinical features of patients infected with 2019 novel coronavirus in Wuhan, China. Lancet 2020;395 (10223):497-506

17 Donnelly CA, Ghani AC, Leung GM, et al. Epidemiological determinants of spread of causal agent of severe acute respiratory syndrome in Hong Kong. Lancet 2003;361(9371):1761-1766

18 Leung TF, Wong GWK, Hon KLE, Fok TF. Severe acute respiratory syndrome (SARS) in children: epidemiology, presentation and management. Paediatr Respir Rev 2003;4(04):334-339

19 Wong CK, Lam CW, Wu AK, et al. Plasma inflammatory cytokines and chemokines in severe acute respiratory syndrome. Clin Exp Immunol 2004;136(01):95-103

20 Mahallawi WH, Khabour OF, Zhang Q Makhdoum HM, Suliman BA. MERS-CoV infection in humans is associated with a pro-inflammatory Th1 and Th17 cytokine profile. Cytokine 2018;104:8-13

21 Wu F, Zhao S, Yu B, et al. A new coronavirus associated with human respiratory disease in China. Nature 2020;579(7798):265-269

22 Channappanavar R, Fehr AR, Zheng J, et al. IFN-I response timing relative to virus replication determines MERS coronavirus infection outcomes. J Clin Invest 2019;130:3625-3639
23 Channappanavar R, Zhao J, Perlman S. T cell-mediated immune response to respiratory coronaviruses. Immunol Res 2014;59(13):118-128

24 Zumla A, Hui DS, Perlman S. Middle East respiratory syndrome. Lancet 2015;386(9997):995-1007

25 Channappanavar R, Perlman S. Pathogenic human coronavirus infections: causes and consequences of cytokine storm and immunopathology. Semin Immunopathol 2017;39(05):529-539

26 Perlman S, Dandekar AA. Immunopathogenesis of coronavirus infections: implications for SARS. Nat Rev Immunol 2005;5(12): 917-927

27 Kuchar E, Miśkiewicz K, Nitsch-Osuch A, Szenborn L. Pathophysiology of clinical symptoms in acute viral respiratory tract infections. Adv Exp Med Biol 2015;857:25-38

28 Murin CD, Wilson IA, Ward AB. Antibody responses to viral infections: a structural perspective across three different enveloped viruses. Nat Microbiol 2019;4(05):734-747

$29 \mathrm{He}$ W, Tan GS, Mullarkey CE, et al. Epitope specificity plays a critical role in regulating antibody-dependent cell-mediated cytotoxicity against influenza A virus. PNAS 2016;113(42):11931-11936

30 Yang F, Xiao Y, Lu R, et al. Generation of neutralizing and nonneutralizing monoclonal antibodies against $\mathrm{H} 7 \mathrm{~N} 9$ influenza virus. Emerg Microbes Infect 2020;9(01):664-675

31 Pelegrin M, Naranjo-Gomez M, Piechaczyk M. Antiviral monoclonal antibodies: can they be more than simple neutralizing agents? Trends Microbiol 2015;23(10):653-665

32 Kumar D, Romero Y, Schuck KN, Smalley H, Subedi B, Fleming SD. Drivers and regulators of humoral innate immune responses to infection and cancer. Mol Immunol 2020;121:99-110

33 Russell B, Moss C, Rigg A, Van Hemelrijck M. COVID-19 and treatment with NSAIDs and corticosteroids: should we be limiting their use in the clinical setting? Ecancermedicalscience 2020; 14:1023

34 Russell CD, Millar JE, Baillie JK. Clinical evidence does not support corticosteroid treatment for 2019-nCoV lung injury. Lancet 2020; 395(10223):473-475

35 Shang L, Zhao J, Hu Y, Du R, Cao B. On the use of corticosteroids for 2019-nCoV pneumonia. Lancet 2020;395(10225):683-684

36 Zha L, Li S, Pan L, et al. Corticosteroid treatment of patients with coronavirus disease 2019 (COVID-19). Med J Aust 2020 (e-pub ahead of print) . Doi: $10.5694 / \mathrm{mja} 2.50577$

37 Liu WJ, Zhao M, Liu K, et al. T-cell immunity of SARS-CoV: implications for vaccine development against MERS-CoV. Antiviral Res 2017;137:82-92

38 Liu W, Fontanet A, Zhang PH, et al. Two-year prospective study of the humoral immune response of patients with severe acute respiratory syndrome. J Infect Dis 2006;193(06):792-795

39 Zhou G, Zhao Q. Perspectives on therapeutic neutralizing antibodies against the novel coronavirus SARS-CoV-2. Int J Biol Sci 2020;16(10):1718-1723

40 Lin Q Zhu L, Ni Z, Meng H, You L. Duration of serum neutralizing antibodies for SARS-CoV-2: lessons from SARS-CoV infection. J Microbiol Immunol Infect 2020 (e-pub ahead of print) . Doi: 10.1016/j.jmii.2020.03.015

41 Du L, Yang Y, Zhou Y, Lu L, Li F, Jiang S. MERS-CoV spike protein: a key target for antivirals. Expert Opin Ther Targets 2017;21(02): 131-143

42 Shanmugaraj B, Siriwattananon K, Wangkanont K, Phoolcharoen W. Perspectives on monoclonal antibody therapy as potential therapeutic intervention for Coronavirus disease-19 (COVID-19). Asian Pac J Allergy Immunol 2020;38(01):10-18

43 Tang XC, Marasco WA. Human neutralizing antibodies against MERS coronavirus: implications for future immunotherapy. Immunotherapy 2015;7(06):591-594

44 Tang J, Zhang N, Tao X, et al. Optimization of antigen dose for a receptor-binding domain-based subunit vaccine against MERS coronavirus. Hum Vaccin Immunother 2015;11(05):1244-1250 
45 Tian X, Li C, Huang A, et al. Potent binding of 2019 novel coronavirus spike protein by a SARS coronavirus-specific human monoclonal antibody. Emerg Microbes Infect 2020;9(01): 382-385

46 Hung IFN, To KKW, Lee C-K, et al. Hyperimmune IV immunoglobulin treatment: a multicenter double-blind randomized controlled trial for patients with severe 2009 influenza $A(H 1 N 1)$ infection. Chest 2013;144(02):464-473

47 Arabi YM, Fowler R, Hayden FG. Critical care management of adults with community-acquired severe respiratory viral infection. Intensive Care Med 2020;46(02):315-328

48 Bloch EM, Shoham S, Casadevall A, et al. Deployment of convalescent plasma for the prevention and treatment of COVID-19. J Clin Invest 2020:138745

49 Payne S, ed. Methods to study viruses. In: Viruses from Understanding to Investigation. London: Academic Press; 2017:37-52

50 Luke TC, Kilbane EM, Jackson JL, Hoffman SL. Meta-analysis: convalescent blood products for Spanish influenza pneumonia: a future H5N1 treatment? Ann Intern Med 2006;145(08):599-609

51 O'Malley JJ, Hartman FW. Treatment of influenzal pneumonia with plasma of convalescent patients. J Am Med Assoc 1919;72:34

52 McGuire LW, Redden WR. Treatment of influenzal pneumonia by the use of convalescent human serum: Second report. J Am Med Assoc 1919;72:709

53 Sanborn G. The use of the serum of convalescents in the treatment of influenza pneumonia: a summary of the results in a series of one hundred and one cases. Boston Med Surg J 1920;183:171-177

54 Mair-Jenkins J, Saavedra-Campos M, Baillie JK, et al; Convalescent Plasma Study Group. The effectiveness of convalescent plasma and hyperimmune immunoglobulin for the treatment of severe acute respiratory infections of viral etiology: a systematic review and exploratory meta-analysis. J Infect Dis 2015;211(01):80-90

55 Hung IF, To KK, Lee C-K, et al. Convalescent plasma treatment reduced mortality in patients with severe pandemic influenza $A$ (H1N1) 2009 virus infection. Clin Infect Dis 2011;52(04):447-456

56 Beigel JH, Tebas P, Elie-Turenne M-C, et al; IRC002 Study Team. Immune plasma for the treatment of severe influenza: an openlabel, multicentre, phase 2 randomised study. Lancet Respir Med 2017;5(06):500-511

57 Beigel JH, Aga E, Elie-Turenne MC, et al; IRC005 Study Team. Antiinfluenza immune plasma for the treatment of patients with severe influenza A: a randomised, double-blind, phase 3 trial. Lancet Respir Med 2019;7(11):941-950

58 Cheng Y, Wong R, Soo YO, et al. Use of convalescent plasma therapy in SARS patients in Hong Kong. Eur J Clin Microbiol Infect Dis 2005;24(01):44-46

59 Cormier M, Batty P, Tarrant J, Lillicrap D. Advances in knowledge of inhibitor formation in severe haemophilia $\mathrm{A}$. $\mathrm{Br} \mathrm{J}$ Haematol 2020;189(01):39-53

60 Arabi Y, Balkhy H, Hajeer AH, et al. Feasibility, safety, clinical, and laboratory effects of convalescent plasma therapy for patients with Middle East respiratory syndrome coronavirus infection: a study protocol. Springerplus 2015;4:709

$61 \mathrm{Ko} \mathrm{JH}$, Seok H, Cho SY, et al. Challenges of convalescent plasma infusion therapy in Middle East respiratory coronavirus infection: a single centre experience. Antivir Ther 2018;23(07):617-622
62 Duan K, Liu B, Li C, et al. Effectiveness of convalescent plasma therapy in severe COVID-19 patients. Proc Natl Acad Sci USA 2020 (e-pub ahead of print) . Doi: 10.1073/pnas.2004168117

63 Shen C, Wang Z, Zhao F, et al. Treatment of 5 critically ill patients with COVID-19 with convalescent plasma. JAMA 2020 (e-pub ahead of print) . Doi: 10.1001/jama.2020.4783

64 Tiberghien P, de Lambalerie X, Morel P, Gallian P, Lacombe K, Yazdanpanah Y. Collecting and evaluating convalescent plasma for COVID-19 treatment: why and how. Vox Sang 2020 (e-pub ahead of print) . Doi: 10.1111/vox.12926

65 Zhang JS, Chen JT, Liu YX, et al. A serological survey on neutralizing antibody titer of SARS convalescent sera. J Med Virol 2005;77 (02):147-150

66 Hung IF, To KK, Lee CK, et al. Effect of clinical and virological parameters on the level of neutralizing antibody against pandemic influenza A virus H1N1 2009. Clin Infect Dis 2010;51(03): 274-279

67 Ko JH, Müller MA, Seok H, et al. Serologic responses of 42 MERScoronavirus-infected patients according to the disease severity. Diagn Microbiol Infect Dis 2017;89(02):106-111

68 Nurtop E, Villarroel PMS, Pastorino B, et al. Combination of ELISA screening and seroneutralisation tests to expedite Zika virus seroprevalence studies. Virol J 2018;15(01):192

69 Nurtop E, Villarroel PMS, Pastorino B, et al. Correction to: Combination of ELISA screening and seroneutralisation tests to expedite Zika virus seroprevalence studies. Virol J 2019;16(01):12

70 Smatti MK, Al Thani AA, Yassine HM. Viral-induced enhanced disease illness. Front Microbiol 2018;9:2991

71 U.S. Food and Drug Administration. Investigational COVID-19 convalescent plasma: guidance for industry. Available at: https://www.fda.gov/regulatory-information/search-fda-guidance-documents/investigational-covid-19-convalescent-plasma. Accessed May 6, 2020

72 Ahn DG, Shin HJ, Kim MH, et al. Current status of epidemiology, diagnosis, therapeutics, and vaccines for novel coronavirus disease 2019 (COVID-19). J Microbiol Biotechnol 2020;30(03): 313-324

73 He Y, Zhou Y, Liu S, et al. Receptor-binding domain of SARS-CoV spike protein induces highly potent neutralizing antibodies: implication for developing subunit vaccine. Biochem Biophys Res Commun 2004;324(02):773-781

$74 \mathrm{He} \mathrm{Y,} \mathrm{Zhou} \mathrm{Y,} \mathrm{Wu} \mathrm{H,} \mathrm{et} \mathrm{al.} \mathrm{Identification} \mathrm{of} \mathrm{immunodominant} \mathrm{sites}$ on the spike protein of severe acute respiratory syndrome (SARS) coronavirus: implication for developing SARS diagnostics and vaccines. J Immunol 2004;173(06):4050-4057

75 Kim TW, Lee JH, Hung CF, et al. Generation and characterization of DNA vaccines targeting the nucleocapsid protein of severe acute respiratory syndrome coronavirus. J Virol 2004;78(09):4638-4645

76 Tirado SM, Yoon KJ. Antibody-dependent enhancement of virus infection and disease. Viral Immunol 2003;16(01):69-86

77 Wang SF, Tseng SP, Yen $\mathrm{CH}$, et al. Antibody-dependent SARS coronavirus infection is mediated by antibodies against spike proteins. Biochem Biophys Res Commun 2014;451(02):208-214

78 Wan Y, Shang J, Sun S, et al. Molecular mechanism for antibodydependent enhancement of coronavirus entry. J Virol 2020;94 (05):94 